\title{
Vocal and Physiological Changes in Response to the Physical Attractiveness of Conversational Partners
}

Article in Journal of Nonverbal Behavior · September 2010

DOI: 10.1007/s10919-010-0087-9

CITATIONS

29
READS

557

3 authors, including:

Sally D Farley

University of Baltimore

18 PUBLICATIONS 157 CITATIONS

SEE PROFILE

Some of the authors of this publication are also working on these related projects:

Project

Are nonverbal engagement signals or self-reported attitudes better predictors of behavior? View project 


\title{
Vocal and Physiological Changes in Response to the Physical Attractiveness of Conversational Partners
}

\author{
Susan M. Hughes $\cdot$ Sally D. Farley $・$ Bradley C. Rhodes
}

Published online: 11 April 2010

(C) Springer Science+Business Media, LLC 2010

\begin{abstract}
We examined how individuals may change their voices when speaking to attractive versus unattractive individuals, and if it were possible for others to perceive these vocal changes. In addition, we examined if any concurrent physiological effects occurred when speaking with individuals who varied in physical attractiveness. We found that both sexes used a lower-pitched voice and showed a higher level of physiological arousal when speaking to the more attractive, opposite-sex target. Furthermore, independent raters evaluated the voice samples directed toward the attractive target (versus the unattractive target) as sounding more pleasant when the two voice samples from the same person presented had a reasonably perceptually noticeable difference in pitch. These findings may have implications for the role voice plays in mate selection and attraction.
\end{abstract}

Keywords Vocal changes - Attractiveness - Voice · Physiological responses · Romantic attraction

\section{Introduction}

The sound of a person's voice can communicate a wealth of biologically and socially important information to potential mates. For instance, the voices of those with greater bilateral body symmetry are rated as sounding more attractive than those possessing less symmetrical features, and body symmetry has been shown to be a marker of developmental fitness (Hughes et al. 2002). Vocal attractiveness is also significantly correlated with other physical markers of fitness and hormonal status (e.g., waist-to-hip ratio in women and shoulder-to-hip ratio in men), in addition to predicting numerous sexual behaviors (Hughes et al. 2004). Hughes et al. (2004) found that for both sexes, those with more attractive voices reported having sex at an earlier age, more sexual partners, and more sexual

S. M. Hughes $(\bowtie) \cdot$ B. C. Rhodes

Department of Psychology, Albright College, Reading, PA 19612, USA

e-mail: shughes@alb.edu

S. D. Farley

University of Baltimore, Baltimore, MD 21201, USA 
infidelity than those with less attractive voices. Individuals also tend to associate positive personality traits with those who have more attractive voices (Zuckerman and Driver 1989). For instance, individuals with attractive voices are thought to be warmer, more likable, honest, dominant, and more likely to achieve (Berry 1990; Zuckerman and Driver 1989).

The fundamental frequency of the voice (i.e., the pitch) is one measure of voice attractiveness that has been extensively examined, but there is no overwhelming consensus in the literature as to what constitutes an "attractive voice." Daniel and McCabe (1992) found that mid-pitched voices for both sexes were perceived as being the "most sexy," suggesting that voices with pitches that deviated too far from the average (within each sex's normal voice pitch range) could indicate hormonal abnormalities. Oguchi and Kikuchi (1997) found that both males and females evaluated a lower-pitched voice with a small pitch range for both sexes as attractive, but Oksenberg et al. (1986) found the opposite, a high pitch with greater variation was associated with voice attractiveness for both sexes.

Other studies suggest distinct sex differences with regards to pitch preferences for opposite-sex voices. Women perceive high-pitched male voices to be unattractive (Riding et al. 2006) and prefer deeper male voices (Collins 2000; Feinberg et al. 2005; Riding et al. 2006), especially during the most fertile phase of their menstrual cycles (Puts 2005). The preference for lower-pitched male voices also appears to be replicated cross-culturally and in Non-Western societies (Apicella et al. 2007; Karpf 2006). Men, on the other hand, perceive higher-pitched female voices as sounding more attractive (Collins and Missing 2003; Feinberg et al. 2008; Jones et al. 2008). Female voices appear to change across the menstrual cycle (Amir et al. 2006), and their voices are perceived as sounding more attractive when they are in the most fertile part of their cycle (Pipitone and Gallup 2008). These findings suggest that women may engage in non-conscious voice manipulation to increase their attractiveness to others during the most critical time of their menstrual cycles, despite not having knowledge of when that fertile time may be.

There is a body of evidence to suggest that individuals manipulate their voices when speaking to different people and in different situations. For instance, women's voices sound more competent when speaking to their bosses rather than to their subordinates or peers, whereas men's voices sound more competent when speaking to their peers (Steckler and Rosenthal 1985). Individuals also tend to raise the pitch of their voice when attempting to deceive another person (Ekman et al. 1976; Streeter et al. 1977) and the more confident individuals are when providing answers to questions, the faster and louder their voices are when they respond (Kimble and Seidel 1991). There is also evidence that individuals speak to males and females differently, whereby others rate vocal samples directed towards men as sounding more dominant and formal than samples directed towards women (Hall and Braunwald 1981). Furthermore, individuals are highly accurate at determining the affect of a speaker based solely on vocal cues such as fundamental frequency, range, amplitude, variability, and tempo (see Scherer 1986 for review).

Given the evidence that there are distinct pitch preferences for men and women, and the studies documenting vocal changes as a function of motivational context, it seems reasonable to expect that men and women would change their voices when confronted by individuals they find attractive. However, research investigating vocal changes in romantic contexts and mate attraction is limited. Montepare and Vega (1988) showed that women were rated as sounding more approachable, sincere, submissive, and scatterbrained when talking to intimate male partners than when talking to male friends during telephone conversations. Furthermore, in an experimental setting, Anolli and Ciceri (2002) showed 
that men who had greater vocal modulation and a gradual deepening of their voices during conversations with women they did not know, were more successful at getting future dates (Anolli and Ciceri 2002). In addition, more self-perceived physically dominant males lowered the pitch of their voices in response to a competitor in a dating game scenario, whereas males who considered themselves to be less physically dominant raised their pitch when confronted with a male competitor (Puts et al. 2006). But the question remains as to whether individuals manipulate aspects of their voices (whether consciously or not) while talking to individuals they find attractive in order to make the tonal qualities of their voice sound better so as to increase their mate value. In Snyder et al.'s (1977) seminal study on the self-fulfilling prophecy, men interacted with women who they believed were either high or low in physical attractiveness. Independent raters evaluated men as more social and friendly when they interacted with "physically attractive" women than when they interacted with less attractive individuals, based solely on vocal samples. Similarly, with regards to vocal changes, since males with lower-pitched voices (Collins 2000; Feinberg et al. 2005; Riding et al. 2006) and females with higher-pitched voices (Collins and Missing 2003; Feinberg et al. 2008; Jones et al. 2008) are rated as sounding more attractive, perhaps we may also expect males will lower and females will raise their voices in order to sound more attractive to a person that they find attractive and want to romantically impress.

Interpersonal attraction may not only motivate us to change our vocal characteristics, but there is also indirect evidence that attraction prompts changes in physiological responses. There is a tendency for people to associate arousal (e.g., increased heart rate) with the encounter of an opposite-sex person they find attractive (Valins 1967). Yet, to date, there is little research that provides concrete evidence of this commonly known postulation that physiological responses directly result from the exposure to attractive, viable mates of the opposite-sex. Heart rate has been shown to increase in response to pleasant, arousing (erotic) pictures (Winton et al. 1984). Hess and Polt (1960) were among the first to report greater pupil dilation (a measure of physiological arousal) in participants viewing semi-nude photos of the opposite sex versus the same sex. There are also distinct neurological patterns that occur when viewing familiar individuals as opposed to intimate partners (Aron et al. 2005) and a strong neurological response to hearing members of the opposite sex speaking in an erotic tone of voice (Ethofer et al. 2007). Sexual arousal can also cause us to be more attentive to the physical attractiveness of opposite-sex individuals. Participants exposed to erotic pictures of the opposite sex later rated non-sexual photographs of average and attractive opposite-sex targets as being even more attractive, and unattractive individuals as being even less attractive than did the control group (Istvan et al. 1982). Nonetheless, our study is among the first to examine whether actual physiological changes occur due to exposure to an attractive individual versus unattractive individual.

While previous investigations are lacking with regards to showing actual physiological changes occurring as a function of the target's attractiveness, several studies have investigated the effects of false feedback arousal on impressions of attractiveness. Valins (1967) showed that the mere belief that one's heartbeat is changing, regardless of actual physiological changes, is sufficient to affect behavior and produce higher ratings of the attractiveness of a person of the opposite-sex. A replication of Valins' study concluded that the increased attention towards physiological reactions had precipitated actual physiological changes (Stern et al. 1972). Woll and McFall (1979) further confirmed that false feedback can produce real physiological responses. When participants were given false heart-rate feedback, their own heart rate also increased, but a corresponding change in 
galvanic skin response (GSR) did not occur. Therefore, GSR may be better index of actual physiological response since it is less influenced by peripheral information such as false feedback.

In the present study, we examined how individuals may change their voices when speaking with an attractive versus unattractive individual, and if it is possible for others to perceive these changes in their voices. In addition, we examined any concurrent physiological effects that may occur when speaking with individuals who varied in physical attractiveness. We hypothesized that males and females will alter their voices when communicating with the more attractive persons, whereby males will lower the pitch of their voices and females will increase the pitch of their voices in order to sound more attractive to those targets. We also predicted that independent raters would be able to perceive these vocal changes and rate the voices of those speaking with the attractive targets as sounding more pleasant. Lastly, we expected that individuals would show a greater physiological arousal as measured by galvanic skin response (GSR) when speaking with attractive persons as an indication of their interpersonal attraction to that target. Galvanic skin response (GSR) is a commonly used measure to assess physiological responses to different stimuli, and research has generally associated a higher GSR with pleasant emotion (Uchiyama et al. 1990). However, since GSR is extremely unspecific, any emotion or even association, whether positive or negative, may lead to an enhanced GSR (Bartels and Zeki 2000).

\section{Method}

\section{Participants Providing Voice Samples}

Forty-eight participants (males $=20$, females $=28$ ) were recruited from Albright College for the first part of the study so that their voices could be recorded while making phone calls to different persons. The mean age of the callers was 21.6 , $(S D=5.4$, range $=18$ 40). Of the participants, $79.2 \%$ self-identified as Caucasian, $12.5 \%$ African American, $6.3 \%$ Asian, and $2.1 \%$ Hispanic. The majority of the callers indicated that they were most sexually attracted to the opposite sex (97.9\%). A total of three female callers were excluded from all analyses due to either having strong accent since English was not their native language or due to a poor voice-recording quality, yielding a total of 45 voice samples (20 males, 25 females).

\section{Procedure for Callers}

After obtaining informed consent, callers completed a brief demographic questionnaire. Then participants were asked to serve as "callers" for a phone survey. They were instructed that they were going to make phone calls to three individuals and ask them a set of four standard questions regarding perceptions of the study of psychology (i.e., "Have you ever taken any psychology courses in your lifetime?"; "Do you know any people who have a career in a psychology profession?"). In the event that respondents failed to answer, callers were instructed to leave a brief standard voice message. Since persons being called were fictitious and part of the deception of the experiment, all calls went to a default voicemail and callers always left messages. As a result, the psychology questions were never asked. Before making each phone call, the caller was presented with a slideshow shown on the screen of a computer monitor of the picture of the person they were calling, 
along with the set of 4 standard questions they were to ask, and a script of the message they should leave if the person did not answer and the call went to voicemail: "Hello. I am calling from Albright College Psychology Department to ask you questions for a phone survey. Someone will try to call you back at another time. Thank you." The phone calls were placed using Skype internet phone service and it was explained to the callers that the targets were derived from a pool of volunteers who agreed to take part in this phone survey and had already provided their pictures. Since there were no actual respondents, we obtained the pictures used for this study from the internet. All of the calls went to the default voicemail message of Skype.com so that a message would always be recorded for each phone call made. The deception appeared to be successful because, before being debriefed, many callers offered to call more individuals since the three persons they called were unavailable and were surprised to hear that the people they were calling were not actual people once they were debriefed. Each of the three phone calls was recorded on Freecorder 2.0 software using a Gigaware USB desktop microphone while the callers were leaving messages.

The pictures used for this study were frontal face photographs of three males and three females that we standardized for size, shape, and color (black and white). These pictures served as our conditions for each sex, one of an attractive person, one of unattractive person and one of an average-attractive individual used as the first trial-run. Therefore, each caller provided three voice samples of messages left for each opposite-sex target. Each of the pictures was previously rated for attractiveness by independent raters. To confirm that our attractiveness manipulation was successful, callers were asked to rate the attractiveness of each person called on a 5-point Likert scale once the study was concluded and their ratings had corroborated with the previous independent ratings for attractiveness. Callers' ratings for the attractiveness of each photograph was significantly different from one another, $F(2,94)=117.09, p=.00, \eta^{2}=.81$. Callers rated the attractive photo $(M=4.36, S D=.74)$ as significantly higher than both the unattractive photo $(M=2.04$, $S D=.71), t(44)=13.32, p=.00$, and the average photo $(M=2.89, S D=.75)$, $t(44)=8.78, p=.00$, and ratings for the average photo $(M=2.89, S D=.75)$ also significantly exceeded ratings for the unattractive photo $(M=2.04, S D=.71), t(44)=7.68$, $p=.00$.

While participants were making the phone calls, their galvanic skin response (GSR) was also being monitored during each call and for $30 \mathrm{~s}$ baselines before each call using iWorx recording devices interfaced with LabScribe II. Skin conductance was recorded using $\mathrm{Ag} / \mathrm{AgCl}$ electrodes attached to the volar surface of the third digit of the left hand and absolute measures of skin conductance were recorded (a procedure followed by Taylor et al. 2000). Callers were told that their hands and body should remain as still as possible and that their physiological measures were going to be recorded in order to determine if callers experience physiological change as a function of respondents' answers. Due to equipment malfunction, the first thirteen physiological recordings were not properly obtained, thereby yielding physiological measures for a total of 32 callers (13 males and 19 females). Once all voice recordings were obtained, Praat 5.30 voice software was used to conduct pitch analysis on each of the voice samples.

Callers were only shown pictures of opposite-sex individuals, with the neutrallyattractive condition always appearing first, and the attractive and unattractive targets counterbalanced in sequence thereafter. Callers were always presented with a neutral target first as sort of a trial-run because we expected that having to conduct phone calls with strangers would elicit an elevated anxiety and would impact our findings. Our hope was that anxiety levels would decrease dramatically after callers initiated their first calls. Our 
analysis of GSR confirmed this was the case since the mean change in GSR from baseline for the neutral condition $(M=1.39, S D=1.31)$ substantially exceeded changes for both the attractive $(M=.38, S D=1.30), t(30)=3.38, p=.00$, and the unattractive conditions $(M=-.13, S D=.60), t(30)=5.60, p=.00$. Therefore, we considered only the comparison of the attractive and unattractive conditions for the response analyses.

\section{Subjective Raters}

An additional 39 participants $($ male $=12$, female $=27$ ) served as independent raters to judge the voice recordings obtained from the callers and provide subjective ratings for pitch level and voice pleasantness. The mean age of the raters was 23.3 ( $S D=8.6$, range 17-59). The majority of raters were Caucasian (74.4\%), followed by African American $(15.4 \%)$, Hispanic $(2.6 \%)$ and $7.7 \%$ indicated they were of another ethnicity.

\section{Procedure for Subjective Raters}

The voice recordings obtained from the callers were cropped to include only the initial greeting of the caller saying "Hello" and were presented to independent raters. Previous studies have demonstrated that several subjective ratings such as voice attractiveness, age, body morphology, etc. can be determined by hearing relatively short segments of speech such as a word, vowel sound, or number count (Collins 2000; Hughes et al. 2004; Kramer 1963, 1964). Furthermore, we expected that the initial greeting of "Hello" would show the most variability during the message and perhaps represent the most "natural" part of the message, providing the highest ecological validity. The "hello" segment was also used for the pitch analysis, which is usually conducted on fairly short segments. Using short segments for pitch analysis was an attempt to eliminate the difficulty of analyzing boundaries between words, and follows the procedures of several similar investigations examining pitch differences (Apicella et al. 2007; Collins and Missing 2003; Feinberg et al. 2005, 2008).

The neutral-condition recordings were excluded since they served as a control and were always presented first to the callers so as to familiarize them with the procedure and to improve the quality of the subsequent voice samples. Independent raters were presented with paired samples of the voice recordings from each caller (one to attractive target, one to unattractive target) so that the raters could make direct comparisons between the two voice samples. Each paired set was presented three times for rating accuracy. Raters were asked to choose which of the two voice samples sounder lower-pitched and also which sounded more pleasant. The presentation of all voice samples and which condition was played first (attractive versus unattractive) was counterbalanced for raters. Raters were tested in small groups ranging from 1-6 persons in a private, quiet testing room setting.

\section{Results}

Objective Pitch Analysis

The fundamental frequency, as measured by the $\mathrm{F}_{0}$ component of Praat, was significantly lower, regardless of gender of speaker, when leaving a message for attractive targets $(M=208.84 \mathrm{~Hz}, S D=69.58)$ than unattractive targets $(M=215.44 \mathrm{~Hz}, S D=72.38)$, 
$t(44)=-2.98, p=.00$. The same difference held true when examining median pitch of the voice recordings; callers' median pitch was lower in response to attractive targets $(M=204.82 \mathrm{~Hz}, S D=68.48)$ than to unattractive targets $(M=211.15 \mathrm{~Hz}, S D=73.26)$, $t(44)=-2.28, p=03$.

In order to consider sex differences, a 2 (target condition) $\times 2$ (sex of voice) mixedmodel ANOVA was used to examine mean voice pitch. A main effect for condition remained, $F(1,43)=8.07, p=.01, \eta^{2}=.16$, with participants lowering their voice for attractive targets $(M=208.84 \mathrm{~Hz}, S D=69.58)$ than for unattractive targets $(M=215.44 \mathrm{~Hz}, S D=72.38)$. There was also a main effect for sex, $F(1,43)=136.05$, $p=.00, \eta^{2}=.76$, with males $(M=144.10 \mathrm{~Hz}$., $S D=7.82)$ generally having overall lower-pitched voices than females $(M=266.57 \mathrm{~Hz} ., S D=7.00)$. However, no significant interaction was found between these two variables, $F(1,43)=3.17, p=.08$, suggesting that both sexes equally lowered the pitch of their voices when talking to the attractive target. As shown in Fig. 1, the mean pitch for male voices directed toward the attractive target was lower $(M=142.95 \mathrm{~Hz} ., S D=37.70)$ than directed towards the unattractive target $(M=145.25 \mathrm{~Hz} ., S D=36.30)$. Similarly, as seen in Fig. 2, the mean pitch for female voices directed toward the attractive target was also lower $(M=261.55 \mathrm{~Hz}$., $S D=35.19)$ than directed towards the unattractive target $(M=271.59 \mathrm{~Hz} ., S D=34.21)$.

\section{Subjective Ratings}

Raters were presented with two voice samples from each caller (a voice sample obtained when speaking to the attractive target and to the unattractive target) and were asked to (1) choose which voice sample sounded lower-pitched and (2) choose which voice sample sounded more pleasant. The proportion of raters who correctly chose the lower-pitched voice recording was tallied. We analyzed the proportion of raters who judged correctly between the two voice samples against a 50\% chance level, using single sample t-tests. Raters were significantly better than chance at identifying which recording was the lowerpitched voice sample for the majority of callers' voice recordings $(M=59.44 \%$, $S D=19.11), t(44)=3.31, p=.00$. Similarly, we tallied the number of raters who had chosen the voice sample directed towards the attractive versus unattractive targets as sounding lower pitched. A greater proportion of raters were also more likely than chance to

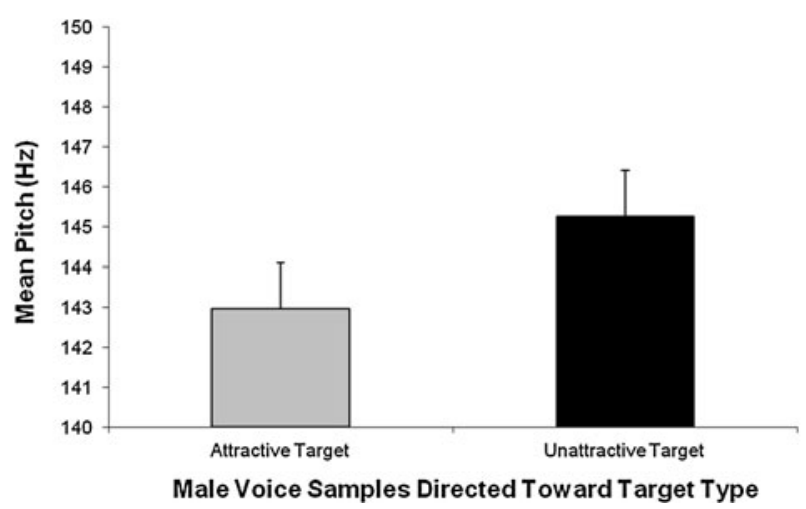

Fig. 1 Differences in fundamental frequency (mean pitch) of voice samples obtained from male callers speaking to an attractive and unattractive individual 


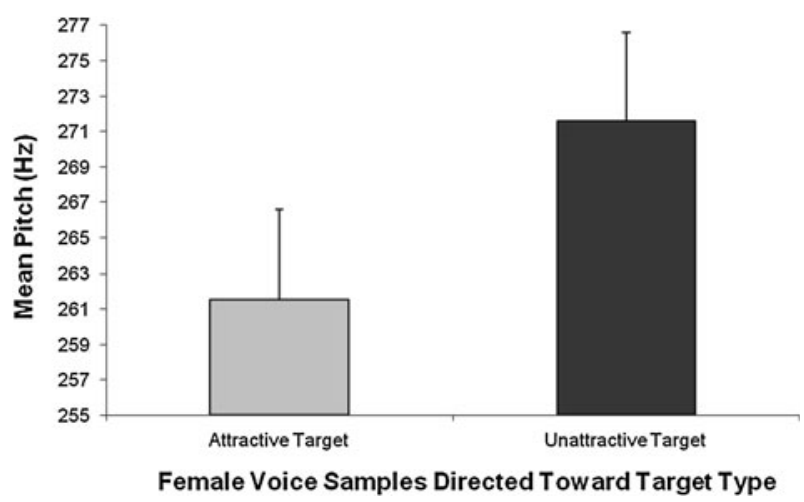

Fig. 2 Differences in fundamental frequency (mean pitch) of voice samples obtained from female callers speaking to an attractive and unattractive individual

correctly select the voice recording directed toward the attractive target as sounding lower pitched $(M=58.23 \%, S D=19.67), t(44)=2.81, p=.01$. Furthermore, we totaled the number of raters who chose the lower versus higher pitched voice recordings as sounding more pleasant and found that raters were more likely than chance to choose the lower pitched voice recording as sounding more pleasant $(M=54.56 \%, S D=14.05)$, $t(44)=2.18, p=.04$.

We also tallied the proportion of raters who chose the voice sample directed toward the attractive target as sounding more pleasant. Raters were not more likely than chance to choose the voice recording directed toward the attractive target as sounding more pleasant $(M=51.36 \%, S D=14.72), t(44)=.62, p=.54, n s$. However, this may be explained by the lack of pitch discrepancy between some of the paired samples. In other words, making the distinction of voice pleasantness may require a rather noticeable difference in pitch between the two recordings before an assessment can be made [see Ladefoged (1996) for JND frequency ranges of normal voices]. In support of this idea, the greater the discrepancy in actual pitch between recordings directed toward the attractive and unattractive targets, the more likely the rater chose the voice recording directed toward the attractive target as sounding more pleasant, $r=.37, p=.01$. Furthermore, as the discrepancy in actual pitch between the two recordings increased, the more pleasant the voice was rated if it came from the lower pitched recording, $r=.31, p=.04$. There was no sex difference found in any of these analyses.

\section{Galvanic Skin Response}

Physiological measures of skin conductance of the callers were taken for a baseline of $30 \mathrm{~s}$ prior to making each of the three phone calls. Absolute values of skin conductance changes were derived from subtracting the first two-seconds of the phone call from each baseline, approximating when the caller said "Hello" to the target in order to keep analyses consistent with our previous analyses. Callers showed greater physiological change in skin conductance from baseline when speaking to the attractive target $(M=.82, S D=1.07)$ than to the unattractive target $(M=.44, S D=.42), t(30)=2.24, p=.03$. No sex differences were found in these analyses. We also examined if there was a relationship between absolute changes of GSR from each baseline to the first couple of seconds when each phone call was made. As GSR increased, pitch tended to decrease for both the 
attractive $(r(28)=-.09, p=.66)$ and unattractive $(r(28)=-.12, p=.51)$ conditions; however these relationships were not significant.

\section{Discussion}

This study provides evidence that individuals alter their voices as a function of the attractiveness of their conversational partner, such that both sexes tended to lower the pitch of their voices when communicating with more attractive targets. Our findings are consistent with Snyder et al. (1977) who also showed that individuals tend to behave differently when speaking to a person they believe is more attractive. Not only do individuals become more likable and sociable when interacting with attractive targets, but our findings demonstrated that the objective and subjective quality of their voices also change. Furthermore, we showed that people were perceptually capable of correctly identifying a lower-pitched voice between rather similar voice samples obtained from the same person. Raters also judged the voice sample of the caller speaking to the attractive person as sounding more pleasant when the voice samples had a reasonably noticeable difference in pitch. These findings may have implications for the important role voice plays in mate selection and attraction. If people can perceive changes in others' voices when speaking to attractive individuals (whether they may be consciously aware of this or not), this perception may be adaptive for identifying interested potential mates, detecting partner interest in others, and possible detection of partner infidelity. These results also support research that has demonstrated the ability of listener/judges to accurately identify roleplayed emotional expression from content-free speech and with minimal auditory information (Kramer 1963, 1964; Davitz 1964).

The tendency to associate a lower-pitched voice as sounding more attractive for male speakers has been well-documented (Feinberg et al. 2005; Puts 2005; Riding et al. 2006) and there appears to be some evidence for a cross-cultural preference for deeper-pitched male voices (Apicella et al. 2007; Karpf 2006). A low-pitch voice for male speakers has been shown to relate to masculinity, higher reproductive fitness, (e.g., lower pitched males sire more children) (Apicella et al. 2007) and increased ratings of men's social and physical dominance (Puts et al. 2006). The pitch of men's voices is negatively correlated with several morphological markers of masculinity including weight, shoulder circumference, chest circumference, and shoulder-to-hip ratio (SHR) (Evans et al. 2006). Males who speak in a lower pitch voice compared to their higher pitched counterparts have also reported having more sexual partners within the last year (Puts et al. 2006). Furthermore, women with higher mate value and who have higher self-reported attractiveness prefer males with more masculine, lower pitched voices (Vukovic et al. 2008). Therefore, it may be an advantageous manipulation on the part of males to lower their voices in order to obtain females with greater mate value.

Contrary to our hypothesis, we found that females did not raise, but also lowered the pitch of their voice when talking to the more attractive target. There is a body of literature showing females with higher-pitched voices are judged to sound more attractive by males (Collins and Missing 2003; Feinberg et al. 2008; Jones et al. 2008). Therefore, it seems counterintuitive that the female participants in our study lowered their voices in attempt to sound more attractive toward our attractive target stimuli. However, some research has shown a male preference for lower-pitched female voices (Leaderbrand et al. 2008; Oguchi and Kikuchi 1997) and there appears to be a common stereotype in our culture that deems a sexy female voice as one that sounds husky, breathy, and lower-pitched (Karpf 2006). 
For instance, Tuomi and Fisher (1979) conducted a study where they asked participants to simulate a "sexy voice", and both sexes greatly decreased the pitch of the voices in order to sound more sexy, with females lowering the fundamental frequency of their voices even more (by $25 \mathrm{~Hz}$ ) than did the male participants (by $20 \mathrm{~Hz}$ ). This suggests that the motivation to display a sexy/seductive female voice may conflict with the motivation to sound more feminine and/or reproductively fit.

Furthermore, the preference for a higher-pitched female voice is not necessarily a crosscultural predilection as there is some cultural variability for female pitch preference. For example, Swedish $(M=196 \mathrm{~Hz})$ and Dutch $(M=191 \mathrm{~Hz})$ women tend to speak in much lower tones than American women $(M=214 \mathrm{~Hz})$, and medium and low-pitched female voices are thought to sound more attractive than higher pitched voices in those cultures (Van Bezooijen 1995). Moreover, average women's voices have significantly deepened over the past 50 years in America; recordings assessing the average pitch of women aged 18-25 made in $1945(M=229 \mathrm{~Hz})$ were significantly higher than that of a cohort group made in $1993(M=206 \mathrm{~Hz})$ (Pemberton et al. 1998). It was suggested that some of this deepening of voices by women may have been conscious and the result of such influences as voice coaches, sound engineers, mass media/broadcasting announcers, and overall cultural pressures (Karpf 2006). Rousey and Moriarty (1965) suggested that voice qualities reflect a speaker's intent to project a certain gender image and perhaps adoption of a below-normal pitch level for females may indicate a more masculine role in life, and may be a byproduct of women recently becoming more involved in traditionally male-oriented occupational roles in our culture (Karpf 2006).

So if the stereotype that deepening one's voice allows both sexes to sound more attractive holds true, it may explain why the callers in our study lowered the pitch of their voices when leaving a message for the attractive opposite-sex targets so as to sound more attractive. Indeed, our raters judged the lower-pitched voice sample for both male and female callers as sounding more pleasant. For males, it has been shown that a deepening of the voice is successful for obtaining mates (Anolli and Ciceri 2002). For females, the discrepancy between their attempt to sound attractive by deepening their voice and the overall preference for higher-pitched female voices suggests that voice manipulation may be a learned behavior based on sexual voice stereotypes rather than actual vocal characteristics of attractiveness. One should also consider that there could be a distinction between making comparisons between individuals (whereby higher-pitched female voices are preferred), and making subtle comparisons between different voice samples obtained from the same person who have naturally changed their voice in reaction to a person/ situation (where the lower-toned voice is preferred). Perhaps when a woman naturally lowers her voice, it may be perceived as her attempt to sound more seductive or attractive, and therefore serves as a signal of her romantic interest.

In support of this idea, studies have shown that factors indicating female interest can trump male preference for higher female pitch. For instance, Jones et al. (2008) showed that higher pitched voice samples were preferred by men when a woman was saying "I really like you" but not as much when saying "I really don't like you," demonstrating the important role that content/semantics of speech play with regard to males' pitch preferences. Alternatively, an equivalent study conducted on male voices showed that females had a preference for a lower pitched male voice regardless of the phrase indicating interest (i.e., "I really like you") or not (Vukovic et al. 2008).

Because our study only examined responses to only opposite-sex pairs, and there is no comparative same-sex group, we cannot be fully certain if men and women speak differently to opposite-sex targets or if people simply speak differently to men versus women. 
Even though the interaction between sex and target condition (attractive versus unattractive) was not significant, it seemed that females lowered the pitch of their voices when talking to the opposite-sex attractive target a bit more than did males. It is important to acknowledge that people speak differently to males versus females. For instance, Hall and Braunwald (1981) showed that both male and female speakers speak more dominantly, condescendingly, and unpleasantly to males rather than to females, despite perceivers thinking that females would speak more dominantly to other female targets.

Our findings are among the first to empirically demonstrate that a higher degree of physiological response occurs when one is confronted with a more attractive individual. Previous research suggests that people associate physical attractiveness in the opposite sex with their own increased physiological arousal (Stern et al. 1972; Valins 1967; Woll and McFall 1979). Similarly Bartels and Zeki (2000) showed that galvanic skin responses towards pictures of a loved partner was significantly higher than to pictures of friends and concluded that this reveals a differential emotional response to the partner compared to the friends. Nonetheless, to our knowledge, there is little empirical evidence which shows that physiological arousal directly results from being confronted with an attractive individual prior to this study. This finding is important as it relates to mate selection. It is adaptive to find mates with superior genes to pass onto one's offspring and the physiological response toward attractive individuals is one proximate mechanism that allows us to select those viable mates.

GSR is extremely unspecific and any emotion or even association, whether positive or negative, may lead to an enhanced GSR (Bartels and Zeki 2000). Therefore, another interpretation as to why participants showed a greater physiological response when speaking to the attractive target was because they might have felt anxious when talking to a very attractive person, especially since the target photos shown were of those rated as being extremely attractive by both independent raters and later by the participants. Alternatively, because high attractiveness is a marker for social status (Zuckerman and Driver 1989), perhaps GSR was reflecting their emotional response to an "important" versus "unimportant" target. Therefore, we cannot conclude whether attraction to the target was the mediator of this effect or if attractiveness may have stimulated thoughts and feelings that produced GSR changes. Nonetheless, it is interesting to speculate that changes in GSR may be seen as the physiological counterpart to the vocal changes in pitch seen as the overall response to the attractive targets. However, when directly comparing GSR to pitch changes, there was no significant correlation, suggesting that one does not exactly map onto changes in the other.

Future research should focus on increasing the external validity of these findings by examining whether these vocal differences occur between individuals who are communicating in person and by studying natural conversational interactions. Furthermore, the attractiveness of the conversational partner's voice could also have an effect on how a person changes his or her voice in response to an individual. Additionally, we only examined initial greetings and it is possible that other cues may arise and be detected by others during other parts of a more lengthy conversation. Perhaps manipulating the motivational component or intent of a conversation between individuals (i.e., dating partners, competence) would also help explain how individuals change their voices in response to their immediate environment.

Acknowledgments We wish to thank David Osgood and The Summer Albright College Research Experience Program (ACRE) for their support of this research, Rodney Warfield for his assistance in obtaining participants for this study, and Andrea Chapdelaine for helpful comments with analysis. 


\section{References}

Amir, O., Biron-Shental, T., \& Shabtai, E. (2006). Birth control pills and nonprofessional voice: Acoustic analyses. Journal of Speech, Language and Hearing Research, 49(5), 1114-1126.

Anolli, L., \& Ciceri, R. (2002). Analysis of the vocal profiles of male seduction: From exhibition to selfdisclosure. Journal of General Psychology, 129, 149-169.

Apicella, C. L., Feinberg, D. R., \& Marlowe, F. W. (2007). Voice pitch predicts reproductive success in male hunter-gatherers. Biology Letters, 3, 682-684.

Aron, A., Fisher, H., Mashek, D. J., Strong, G., Li, H., \& Brown, L. L. (2005). Reward, motivation, and emotion systems associated with early-stage intense romantic love. Journal of Neurophysiology, 94, 327-337.

Bartels, A., \& Zeki, S. (2000). The neural basis of romantic love. NeuroReport, 11, 3829-3834.

Berry, D. (1990). Vocal attractiveness and vocal babyishness: Effects on stranger, self and friend impressions. Journal of Nonverbal Behavior, 14, 141-153.

Collins, S. A. (2000). Men's voices and women's choices. Animal Behaviour, 60, 773-780.

Collins, S. A., \& Missing, C. (2003). Vocal and visual attractiveness are related in women. Animal Behaviour, 65, 997-1004.

Daniel, H. J., \& McCabe, R. B. (1992). Gender differences in the perception of vocal sexiness. In J. M. G. van der Dennen (Ed.), The nature of the sexes: The sociobiology of sex differences and the "battle of the sexes"' (p. 55). The Netherlands: Origin Press.

Davitz, J. R. (1964). The communication of emotional meaning. New York: McGraw Hill.

Ekman, P., Friesen, W. V., \& Scherer, K. (1976). Body movements and voice pitch in deceptive interaction. Semiotica, 16, 23-27.

Ethofer, T., Wiethoff, S., Anders, S., Kreifelts, B., Grod, W., \& Wildgruber, D. (2007). The voices of seduction: Cross-gender effects in the processing of erotic prosody. Social Cognitive and Affective Neuroscience, 2, 334-337.

Evans, S., Neave, N., \& Wakelin, D. (2006). Relationships between vocal characteristics and body size and shape in human males: An evolutionary explanation for a deep male voice. Biological Psychology, 72, 160-163.

Feinberg, D. R., DeBruine, L. M., Jones, B. C., \& Perrett, D. I. (2008). The role of femininity and averageness of voice pitch in aesthetic judgments of women's voices. Perception, 37, 615-623.

Feinberg, D. R., Jones, B. C., Little, A. C., Burt, D. M., \& Perrett, D. I. (2005). Manipulation of fundamental and formant frequencies influence the attractiveness of human male voices. Animal Behavior, 69, 561568.

Hall, J. A., \& Braunwald, K. G. (1981). Gender cues in conversations. Journal of Personality and Social Psychology, 40, 99-110.

Hess, E. H., \& Polt, J. M. (1960). Pupil size as related to interest value of visual stimuli. Science, 132, 349_ 350.

Hughes, S. M., Dispenza, F., \& Gallup, G. G., Jr. (2004). Ratings of voice attractiveness predict sexual behavior and body configuration. Evolution and Human Behavior, 25, 295-304.

Hughes, S. M., Harrison, M. A., \& Gallup, G. G., Jr. (2002). The sound of symmetry: Voice as a marker of developmental instability. Evolution and Human Behavior, 23, 173-180.

Istvan, J., Griffitt, W., \& Weidner, G. (1982). Sexual arousal and the polarization of perceived sexual attractiveness. Basic and Applied Social Psychology, 4, 307-318.

Jones, B. C., Feinberg, D. R., DeBruine, L. M., Little, A. C., \& Vukovic, J. (2008). Integrating cues of social interest and pitch in men's preferences for women's voices. Biology Letters, 4, 192-194.

Karpf, A. (2006). The human voice. New York, NY: Bloomsbury Publishing.

Kimble, C. E., \& Seidel, S. D. (1991). Vocal signs of confidence. Journal of Nonverbal Behavior, 15, 99105 .

Kramer, E. R. (1963). Judgment of personal characteristics and emotions from nonverbal properties of speech. Psychological Bulletin, 60, 408-420.

Kramer, E. R. (1964). Elimination of cues in judgments of emotion from voice. Journal of Abnormal and Social Psychology, 68, 390-396.

Ladefoged, P. (1996). Elements of acoustic phonetics (2nd ed.). Chicago: University of Chicago Press.

Leaderbrand, K., Dekam, J., Morey, A., \& Tuma, L (2008). The effects of voice pitch on perceptions of attractiveness: Do you sound hot or not. Winona State University Psychology Student Journal.

Montepare, J. M., \& Vega, C. (1988). Women's vocal reactions to intimate and casual male friends. Personality and Social Psychology Bulletin, 14, 103-113.

Oguchi, T., \& Kikuchi, H. (1997). Voice and interpersonal attraction. Japanese Psychological Research, 39, 56-61. 
Oksenberg, L., Coleman, L., \& Cannell, C. F. (1986). Interviewers' voice and refusal rates in telephone surveys. Public Opinion Quarterly, 50, 97-111.

Pemberton, C., McCormack, P., \& Russell, A. (1998). Have women's voices lowered across time? A crosssectional study of Australian women's voices. Journal of Voice, 12, 208-213.

Pipitone, R. N., \& Gallup, G. G., Jr. (2008). Women's attractiveness varies across the menstrual cycle. Evolution and Human Behavior, 29, 268-274.

Puts, D. A. (2005). Mating context and menstrual phase affect women's preferences for male voice pitch. Evolution and Human Behavior, 26, 388-397.

Puts, D. A., Gaulin, J. C., \& Verdolini, K. (2006). Dominance of sexual dimorphism in human voice pitch. Evolution and Human Behavior, 27, 283-296.

Riding, D., Lonsdale, D., \& Brown, B. (2006). The effects of average fundamental frequency and variance of fundamental frequency on male vocal attractiveness to women. Journal of Nonverbal Behavior, 30 , 55-61.

Rousey, C. L., \& Moriarty, A. E. (1965). Diagnostic implications of speech sounds: The reflections of developmental conflict and trauma. Springfield, IL: Charles C. Thomas.

Scherer, K. R. (1986). Vocal affect expression: A review and a model for future research. Psychological Bulletin, 99, 143-165.

Snyder, M., Tanke, E. D., \& Berscheid, E. (1977). Social perception and interpersonal behavior: On the selffulfilling nature of Social stereotypes. Journal of Personality and Social Psychology, 35, 656-666.

Steckler, N. A., \& Rosenthal, R. (1985). Sex differences in nonverbal and verbal communication with bosses, peers, and subordinates. Journal of Applied Psychology, 70, 157-163.

Stern, R. M., Botto, R. W., \& Herrick, C. D. (1972). Behavioral and physiological effects of false heart rate feedback: A replication and extension. Psychophysiology, 9, 21-29.

Streeter, L. A., Krauss, R. M., Geller, V. J., Olson, C. T., \& Apple, W. (1977). Pitch changes during attempted deception. Journal of Personality and Social Psychology, 35, 345-350.

Taylor, S. F., Liberzon, I., \& Koeppe, R. A. (2000). The effect of graded aversive stimuli on limbic and visual activation. Neuropsychologia, 38, 1415-1425.

Tuomi, S. K., \& Fisher, J. E. (1979). Characteristics of a simulated sexy voice. Folia Phoniatrica, 31, 242249.

Uchiyama, I., Hanari, T., Ito, T., \& Takahashi, K. (1990). Patterns of psychological and physiological responses for common affects elicited by films. Psychologia: An International Journal of Psychology in the Orient, 33, 36-41.

Valins, S. (1967). Emotionality and information concerning internal reactions. Journal of Personality and Social Psychology, 6, 458-463.

Van Bezooijen, R. (1995). Sociocultural aspects of pitch differences between Japanese and Dutch women. Language and Speech, 38, 253-265.

Vukovic, J., Feinberg, D. R., Jones, B. C., DeBruine, L. M., Welling, L. L. M., Little, A. C., et al. (2008). Self-rated attractiveness predicts individual differences in women's preferences for masculine male voices. Personality and Individual Differences, 45, 451-456.

Winton, W. N., Putnam, L. E., \& Krauss, R. M. (1984). Facial and autonomic manifestations of the dimensional structure of emotion. Journal of Experimental Social Psychology, 20, 195-216.

Woll, S. B., \& McFall, M. E. (1979). The effects of false feedback on attributed arousal and rated attractiveness in female subjects. Journal of Personality, 47, 214-229.

Zuckerman, M., \& Driver, R. (1989). What sounds beautiful is good: The vocal attractiveness stereotype. Journal of Nonverbal Behavior, 13, 67-82. 